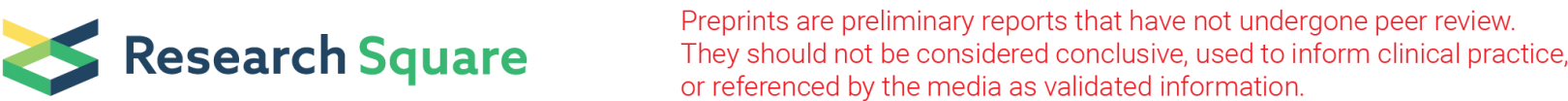

\section{Psychomotor stimulant effects of a- pyrrolidinovalerophenone (aPVP) enantiomers correlate with drug binding kinetics at the dopamine transporter}

Marco Niello ( $\square$ marco.niello@meduniwien.ac.at)

Medical University of Vienna https://orcid.org/0000-0002-0518-5791

Spyridon Sideromenos

Medical University of Vienna

Ralph Gradisch

Ronan O'Shea

Jakob Schwazer

Walter Sandtner

Julian Maier

Kathrin Jäntsch

Carl Lupica

National Institute on Drug Abuse https://orcid.org/0000-0002-5375-3263

Alexander Hoffman

$\mathrm{NIH}$ https://orcid.org/0000-0002-2676-0628

Thomas Stockner

\section{Daniela Pollak}

Medical University of Vienna https://orcid.org/0000-0002-9584-6257

Michael Baumann

Harald Sitte

Medical University of Vienna https://orcid.org/0000-0002-1339-7444

Article

Keywords: a-Pyrrolidinovalerophenone, DAT

Posted Date: June 16th, 2021

DOI: https://doi.org/10.21203/rs.3.rs-612345/v1

License: (c) (1) This work is licensed under a Creative Commons Attribution 4.0 International License.

Read Full License 


\section{Abstract}

a-Pyrrolidinovalerophenone ( $\mathrm{aPVP}$ ) is a psychostimulant and drug of abuse associated with severe intoxications in humans. aPVP exerts long-lasting psychostimulant effects, when compared to the classical dopamine transporter (DAT) inhibitor cocaine. Here, we compared the two enantiomeric forms of aPVP, the R- and the S-aPVP, with cocaine using a combination of in silico, in vitro and in vivo approaches. We found that aPVP enantiomers substantially differ from cocaine in their binding kinetics. The two enantiomers differ from each other in their association rates. However, they show similar slow dissociation rates leading to pseudo-irreversible binding kinetics at DAT. The pseudo-irreversible binding kinetics of aPVP is responsible for the observed non-competitive pharmacology and it correlates with persistent psychostimulant effects in mice. Thus, the slow binding kinetics of aPVP enantiomers profoundly differ from the fast kinetics of cocaine both in vitro and in vivo, suggesting drug-binding kinetics as a potential driver of psychostimulant effects in vivo.

\section{Introduction}

The dopamine transporter (DAT) is a neuronal membrane protein that retrieves previously released dopamine from the extracellular space and moves it back into presynaptic nerve terminals (1). The importance of DAT in the regulation of brain dopaminergic signaling is well established based on decades of in vitro, ex vivo, and in vivo experimental evidences (2-6). From a clinical perspective, singlepoint mutations altering DAT function are associated with a variety of psychiatric disorders, highlighting the importance of DAT in normal and pathological conditions (7-9). Compounds targeting DAT, and other monoamine transporters (MATs), are classified as inhibitors if they bind to the transporter and prevent neurotransmitter uptake, or as releasers if they act as substrates and reverse the normal direction of transporter flux (10). Regardless of their substrate/blocker profile, drugs interacting more selectively with DAT compared to the serotonin transporter (SERT) are typically associated with a higher abusepotential (11). Therefore, the DAT/SERT selectivity ratio is regularly used to predict the abuse-liability of a certain drug (12). In addition to the fundamental substrate/blocker distinction, an emerging complexity for transporter pharmacology has been realized with the discovery of partial substrates (13), allosteric inhibitors (14) and atypical transporter ligands (15).

New psychoactive substances (NPS) represent an important source of pharmacological heterogeneity (16), and are synthetic versions of established drugs of abuse where subtle chemical modifications are introduced to circumvent current legislative control (17).

a-Pyrrolidinovalerophenone (aPVP) is a cathinone-related inhibitor of DAT and the norepinephrine transporter (NET), and devoid of any pharmacological activity at SERT $(18,19)$. The drug was originally patented as a CNS (central nervous system) stimulant but never approved for clinical use, and recently appeared on the clandestine drug market as an NPS (17). The use of aPVP in humans induces psychostimulant effects and can cause severe adverse effects including delusions, paranoia, hallucinations, and deleterious cardiovascular effects (20). Importantly, the pharmacological effects of 
aPVP in humans occur within 10 min after administration of a single dose (15-100 mg) and can last for multiple hours $(20,21)$. A study in humans found that aPVP could still be detected in the bloodstream $6 \mathrm{~h}$ after nasal insufflation and $20 \mathrm{~h}$ after rectal administration (22), and psychotic episodes have been reported as long as 6 days after consumption (23). The sustained clinical effects of aPVP differ substantially from those induced by the plant-based DAT inhibitor cocaine, which has a similar onset of action but much shorter duration of effects $(24,25)$.

Preclinical studies investigating the effects of aPVP in rodents demonstrate avid selfadministration $(26,27)$ and robust place preference $(28)$, together with prolonged stimulatory effects on locomotion (29), blood pressure, and heart rate (18). While aPVP self-administration and conditioned place preference are related to drug activity at DAT, increases in blood pressure and heart rate most likely involve drug activity at NET. aPVP possesses a single chiral center, meaning that it exists as two different enantiomers, the R- and S-isomers. In general, enantiomers have identical physico-chemical properties but a different three-dimensional orientation of the functional groups bound to the chiral carbon, which can confer pronounced differences in pharmacology (30). We and others showed that the cathinone-related NPS, mephedrone, exhibits enantioselective effects at monoamine transporters (31-33), which govern effects of the isomers in vivo $(31,34)$.

Based on preclinical studies with aPVP mentioned above, and previous findings on cathinone enantioselectivity at monoamine transporters, we hypothesized that aPVP enantiomers differ in their binding kinetics at DAT, which might in turn influence psychostimulant activity. Given the established role of DAT in psychomotor processes $(4,15)$ and our interest in the respective psychostimulant effects, we have focused our research on DAT and left the activity at NET to future investigations.

In the present study, we investigated the interactions of aPVP enantiomers with DAT and compared these effects to those of cocaine. Additionally, we related drug interactions at DAT with their psychostimulant correlates in mice. We found that: i) aPVP enantiomers display a time-dependent, non-competitive pharmacology upon interaction with DAT; ii) the non-competitive pharmacology relies on a pseudoirreversible binding kinetics, with slower dissociation rates of aPVP enantiomers compared to cocaine, and implying that the enantio-selectivity of aPVP enantiomers is driven by their association rates; iii) the binding kinetics were also reflected in the longer lasting psychostimulant effects of both aPVP enantiomers in vivo when compared to cocaine.

Overall, our results suggest that binding kinetics represent an under-appreciated property of DAT ligands that can significantly impact the in vivo profile of drug activity and explain their molecular mode of action.

\section{Materials And Methods}

Uptake, binding, molecular biology and electrophysiology experiments have been performed as previously described (35-39). Fast scan cyclic voltammetry procedures were conducted as reported earlier (40). Behavioral experiments were adapted from previously published procedures experiments $(41,42)$. More 
detailed information on the experimental procedures including kinetic and molecular modeling, and all reagents are provided in the material and method section of the Supplementary Information.

\section{Results}

\section{aPVP enantiomers are stereoselective non-competitive inhibitors at DAT}

For our initial experiments, we examined the ability of aPVP isomers (Supp. Fig.1a) to act as inhibitors or substrates at DAT. In DAT uptake inhibition assays carried out in transfected HEK cells, S-aPVP was 125fold more potent $\left(\mathrm{IC}_{50}=0.02 \mu \mathrm{M}\right)$ than R-aPVP $\left(\mathrm{IC}_{50}=2.5 \mu \mathrm{M}\right)$ and 25 -fold more potent than cocaine $\left(\mathrm{IC}_{50}=0.51 \mu \mathrm{M}\right)$. Both aPVP enantiomers were essentially ineffective at inhibiting SERT (S-aPVP IC $\mathrm{C}_{50}$ $=207 \mu \mathrm{M} ; \mathrm{R}^{\mathrm{aPVP}} \mathrm{IC}_{50}=628 \mu \mathrm{M}$ ) and showed no evidence of enantioselectivity in this regard (Supp.

Fig. $1 \mathrm{~b}, \mathrm{c})$. It is well established that DAT substrates induce transporter-mediated inward $\mathrm{Na}^{+}$currents. In an electrophysiological examination of DAT-mediated currents, we found that the cognate substrate dopamine produced robust inward currents whereas neither of the aPVP enantiomers produced this effect. In sum, our initial results confirm that S- and R-aPVP are enantioselective DAT inhibitors with no measurable substrate activity (Supp Fig.1d-f).

Next, we examined the nature of the interaction between aPVP enantiomers and DAT. More specifically, given the low $\mathrm{IC}_{50}$ value observed in the case of DAT, we wished to examine whether the drugs inhibit DAT with a competitive mechanism, similar to cocaine (43), or with a non-competitive mechanism. Previous work shows that cocaine binds to the orthosteric S1-site on DAT, thereby competing with the endogenous substrate dopamine for this site $(44,45)$. Data depicted in Figure 1 confirm that cocaine interacts with DAT in competitive manner, with a concentration-dependent increase in $\mathrm{K}_{\mathrm{m}}$ but no change in $\mathrm{V}_{\max }$ for $\left[{ }^{3} \mathrm{H}\right] \mathrm{DA}$ uptake (Figure 1a-c). By contrast, in the case of the S- and R-enantiomers of aPVP, we found concentration-dependent decreases in $\mathrm{V}_{\max }$ without major changes in $\mathrm{K}_{\mathrm{m}}$ (Figure1d-f and Figure1g-i, respectively), suggesting a non-competitive mechanism of action. Non-competitive inhibition of transporters has been previously reported in the case of allosteric and atypical inhibitors (14).

\section{S-aPVP occupies the S1 orthosteric site of DAT}

Both allosteric and atypical inhibitors can show non-competitive pharmacology. In the case of allosteric modulators, this is due to the presence of a secondary binding site (S2) on the drug target protein that can modify the response of the orthosteric binding site (S1, Fig 2a, top right). Atypical inhibitors instead interact with the orthosteric binding-site but they elicit a conformational re-arrangement of the target which prevents such competition (Fig2a, bottom right). To further elucidate the non-competitive nature of aPVP interactions with DAT, we measured dissociation of the phenyltropane-analogue $\left[{ }^{3} \mathrm{H}\right]$ WIN35428 
from membranes overexpressing human DAT. This experiment is based on the notion that allosteric inhibitors attenuate the dissociation of a radioactive tracer pre-bound into the orthosteric site (14). Similar to the effects of cocaine, the fast dissociation rate of $\left[{ }^{3} \mathrm{H}\right]$ WIN35428 was not affected by the application of aPVP enantiomers (Fig.2b). Since changes to radioligand dissociation rates are dependent on the precise radiotracer employed (46), we also conducted single-point uptake inhibition assays using [ $\left.{ }^{3} \mathrm{H}\right] \mathrm{DA}$ as the radiotracer. Allosteric inhibitors display a greater degree of inhibition when co-incubated with orthosteric ligands (46). Neither of the aPVP enantiomers showed cooperative inhibition (Fig.2c), excluding the possibility of an allosteric mechanism at DAT.

In an attempt to define specific attributes of the binding site for aPVP enantiomers, we applied sitedirected mutagenesis to the DAT central binding site. Given the high DAT/SERT selectivity of aPVP (Supp. Fig.1b), we swapped non-conserved residues between the DAT and SERT central binding site and tested their impact on cocaine, S-aPVP, and R-aPVP activity in uptake-inhibition experiments. We have converted the $\mathrm{IC}_{50}$ values into $\mathrm{K}_{\mathrm{i}}$ values using the Cheng-Prusoff equation (see methods section in the Supplementary Information), in order to account for the effect of the point-mutations on transport efficiency. The Km value for each mutant is reported in the Supplementary Table 1. As shown in Figure $2 \mathrm{~d}-\mathrm{f}$, mutation of DAT phenylalanine 76 to a tyrosine residue (i.e., DAT-F76Y) shifted the inhibition curves of aPVP enantiomers to the right, with a 6-fold increase in the Ki value when compared to DAT wild-type (Fig. 2g; S-aPVP: Ki for DAT-WT $=0.01 \mu \mathrm{M}$ versus $\mathrm{Ki}$ for DAT-F76Y $=0.06 \mu \mathrm{M}$; R-aPVP: Ki DAT-WT = $0.37 \mu \mathrm{M}$ versus Ki DAT-F76Y $=2.19 \mu \mathrm{M})$. This same mutation induced no pharmacologically relevant change in the affinity of cocaine for DAT (cocaine: Ki for DAT WT $=0.20 \mu \mathrm{M}$ versus Ki for DAT F76Y = $0.32 \mu \mathrm{M})$. The Ki values obtained for each mutant are reported in the Supplementary Table 2.

To characterize the precise binding pose of aPVP within the DAT protein, we performed docking experiments of the more potent S-isomer using a homology model of the human DAT (see online Material and Methods). The structure of S-aPVP can be divided into three structural components: an aromatic ring, an aliphatic tail, and a positively charged nitrogen-containing pyrrolidine ring (Figure 2i). The best docked pose of S-aPVP shows that its aromatic ring is located in the S1 binding site between TM3 and TM8 (Figure $2 \mathrm{~h}$ ). This orientation of the aromatic ring is in agreement with the conformations observed for dopamine, amphetamines, and also for inhibitors like cocaine, RTI-55, and nisoxetine $(5,45)$. The hydrophobic side chains of DAT-V152 and DAT-Y156 on TM3 and of DAT-A423 on TM8 stabilize the aromatic ring of S-aPVP by hydrophobic interactions. The aliphatic tail of S-aPVP forms extensive interactions with DAT-F76, which is part of the intracellular hydrophobic gate (Figure $2 \mathrm{~h}$ ). The bulky and positively charged pyrrolidine moiety of S-aPVP instead establishes hydrophobic interactions with DAT1484 and DAT-F320; in addition, the charged nitrogen is interacting with the backbone carbonyl group of DAT-F320 on TM6a that carries a negative partial charge. Overall, our in vitro data suggest that despite showing a non-competitive pharmacology, aPVP enantiomers do not interact with the putative allosteric site but rather with the orthosteric site. Importantly, our mutagenesis study identified one crucial residue, DAT-F76 that selectively impairs the interaction of DAT and APVP enantiomers but not of DA and cocaine. 


\section{aPVP enantiomers display slow dissociation from DAT}

To reconcile the surprising fact that aPVP enantiomers display non-competitive pharmacology but still bind within the orthosteric site, we hypothesized that this might be due to slow binding kinetics, and therefore to a pseudo-irreversible binding mechanism as already described in the case of different Gprotein coupled receptors (47-49). We elicited DAT-mediated currents by applying a saturating DA concentration $(30 \mu \mathrm{M})$ to cells over-expressing the human DAT to examine binding kinetics. Once the steady state DAT-mediated current was established, we co-applied the inhibitor of interest which can reverse the current back to baseline depending on its affinity for DAT and its ability to replace DA (red, gray and blue traces, Figure 3a). After a stable current reversal was established, application of the inhibitor is stopped and $30 \mu \mathrm{M}$ DA is re-applied alone, restoring the current amplitude. The rate of recovery of the current is a measure of the $k_{\text {off }}$ for the inhibitor being tested (dashed box, Figure 3a). As shown in Figure 3a, and in greater detail in Figure 3b, the DA-mediated current recovers fast when cocaine is the tested inhibitor but recovers very slowly in the case of the aPVP enantiomers, indicating a slow dissociation from DAT for aPVP isomers. Given that $\mathrm{Kd}=k_{\text {off }} k_{\text {on }}$ and $\mathrm{Kd}$ generally reflects $\mathrm{Ki}$, we suspect that DAT enantioselectivity of aPVP isomers is based on the different $k_{\text {on }}$ values for each isomer, while the difference between the enantiomers and cocaine is based on their distinct dissociations from DAT.

It was not possible to empirically determine the $k_{\text {on }}$ due to the confounding effects introduced by the saturating concentration of DA necessary to elicit a reliable steady-state current. Indeed, DA is driving DAT through the entire transport cycle, including states in which the inhibitor cannot bind and therefore affecting drug $k_{\text {on }}$. These effects are not problematic in the case of the $k_{\text {off }}$ determination. Here, DA is driving the DAT transport cycle only after the stably bound inhibitor is dissociating based on its $k_{\text {off }}$ which is solely dependent on time $\left(\mathrm{s}^{-1}\right)$. Based on this approach, cocaine showed a $k_{\text {off }}=0.229 \mathrm{~s}^{-1}$, which is very close to the value we previously obtained using a different method ( $\left.k_{\text {off }}=0.35 \mathrm{~s}^{-1} ;(50)\right)$. In contrast, aPVP enantiomers exhibited very slow dissociation rates (S-aPVP $k_{\text {off }}=0.028 \mathrm{~s}^{-1}$ and R-aPVP $k_{\text {off }}=0.051$ $\mathrm{s}^{-1}$ ). Since $\mathrm{S}$ - and R-aPVP exhibit a 125 -fold difference in their $\mathrm{IC}_{50}$ values to inhibit DAT uptake (Supp. Fig1b), yet they show similar $k_{\text {off }}$ measures, we surmise that the enantioselectivity of aPVP at DAT is related to differences in association rates. By contrast, the main differences between cocaine and aPVP enantiomers are related to differences in dissociation rates at DAT. It is important to note that the rate of current inhibition $\left(\mathrm{K}_{\mathrm{app}}\right)$ did not supersede the return-step of the transport cycle $(\mathrm{TiCl}$ à $\mathrm{ToCl})$ estimated to be approximately $1-2 \mathrm{~s}^{-1}((51,52)$; Supp. Fig2). Binding of cocaine requires DAT to be in the outwardfacing conformation (44) which, in presence of the endogenous substrate, can be envisaged with a maximal rate contingent to the rate-limiting step of DAT. On the other hand, if a compound can interact with DAT through the inward-open conformation, $\mathrm{K}_{\mathrm{app}}$ will increase linearly with increasing concentrations, in agreement with a bimolecular reaction (38). However, as expected in the case of 
compounds requiring the outward facing conformation, both cocaine and S-aPVP $\mathrm{K}_{\mathrm{app}}$ saturated at a rate of 1.4 and $1.5 \mathrm{~s}^{-1}$ respectively, which is close to the DAT return step TiCl à ToCl (Supp. Fig2). As such, the analysis of DAT binding kinetics suggests that: i) aPVP enantiomers have substantially slower dissociation rates compared to cocaine, that ii) similar to cocaine, aPVP requires the transporter to be in the outward-facing conformation, and iii) the non-competitive pharmacology might be due to a pseudoirreversible mechanism.

\section{Pseudo-irreversible pharmacology of aPVP enantiomers at DAT}

Kinetic experiments support the hypothesis that aPVP enantiomers interact with DAT in a pseudoirreversible manner. Hence, elongating the uptake time should result in a competitive pharmacology profile. A previously published kinetic model (51) was modified in order to include an inhibitor-bound state (Supp.Fig.2a). The kinetic model reproduced the DAT-mediated current profiles obtained experimentally (Fig.3d), together with the non-competitive pharmacology when the uptake experiments are simulated for 1 min (Fig.3e). In contrast, when the uptake time was increased to $10 \mathrm{~min}$ to account for the slow kinetics of aPVP enantiomers, the model predicted a competitive pharmacological profile (Fig.3f). Therefore, we conducted saturation experiments in HEK293 cells transiently transfected with the human DAT and extended the uptake time from $1 \mathrm{~min}$ to $6 \mathrm{~min}$ (Fig.3g). Under these conditions, we observed competitive pharmacology, i.e. increase in $\mathrm{Km}$ and no changes in Vmax, in presence of aPVP enantiomers and cocaine (control $\mathrm{Km}=2.6 \mu \mathrm{M}$, cocaine $\mathrm{Km}=7.2 \mu \mathrm{M}$, S-aPVP Km = 4.8 $\mu \mathrm{M}$, R-aPVP Km $=3.4 \mu \mathrm{M}$, Fig. $3 \mathrm{~g}-\mathrm{i})$. In the case of R-aPVP, the $\mathrm{K}_{\mathrm{m}}$ increase was not statistically significant.

\section{aPVP enantiomers inhibit dopamine uptake and clearance in rodent brain preparations}

To evaluate whether the DAT binding profile determined in transfected cells is translated to DAT function in native tissue preparations, we evaluated the effects of aPVP enantiomers and cocaine on inhibition of $\left[{ }^{3} \mathrm{H}\right] \mathrm{DA}$ uptake in rat striatal synaptosomes. In agreement with data from HEK cells, S-aPVP was a more potent inhibitor of uptake $\left(S-a P V P I C_{50}=6.9 n M\right)$ than either cocaine $\left(I_{50}=255.2 n M\right)$ or R-aPVP $\left(I_{50}=\right.$ $306.8 \mathrm{nM}$ ) in rat striatum (see Figure 4a). In synaptosomes, we found cocaine and R-aPVP to be nearly equipotent at inhibiting uptake, whereas in HEK cells, cocaine was somewhat more potent. Next, we assessed the ability of the drugs to inhibit DAT in an intact tissue preparation using fast scan cyclic voltammetry (FSCV) in rat striatal slices. Consistent with DAT binding and uptake inhibition results, SaPVP was a more potent inhibitor $\left(\mathrm{IC}_{50}=136 \mathrm{nM}\right)$ of DA clearance when compared to R-aPVP $\left(\mathrm{IC}_{50}=\right.$ $776 \mathrm{nM})$ and cocaine $\left(\mathrm{IC}_{50}=5535 \mathrm{nM}\right)$. However, the potency of R-aPVP to inhibit DA clearance was left- 
shifted compared to cocaine. In general, the data from the rat synaptosome and rat slice experiments agree that S-aPVP is more potent at inhibiting DA clearance and uptake when compared to R-aPVP and cocaine, though there were substantial differences in absolute and relative potencies of the drugs across the two assays.

\section{aPVP enantiomers induce stimulant effects in vivo that reflect binding kinetics in vitro}

Considering the slow dissociation kinetics for both aPVP enantiomers at the human DAT, and the results from rodent synaptosome and slice experiments, we wanted to evaluate if the unique kinetic profile of aPVP enantiomers might influence their in vivo effects. aPVP enantiomers possess the same physicochemical properties, and a similar predicted $\log P$ to cocaine ( $\log P=3.6$ and 3.08 , respectively). Hence, we assumed that the onset of psychostimulant effects using an open-field locomotor activity assay in wild-type C57BI6/N mice, could approximate binding kinetics of aPVP enantiomers and cocaine in vivo. As shown in Figure 5a-c, cocaine, S-aPVP and R-aPVP increased the locomotor activity of C57/BL6-mice in a time- and dose-dependent manner (Figure 5a-c). The cumulative distance traveled over 60 min post i.p. injection led to dose-response curves where S-aPVP was at least 10-fold more potent than R-aPVP and cocaine, consistent with DAT binding and uptake inhibition. In addition, the time-course for locomotor activation revealed the three compounds differed substantially from each other: cocaine and S-aPVP showed a rapid onset of action (0-15 min) when compared to R-aPVP, while the stimulatory effects of both aPVP-enantiomers persisted much longer than cocaine effects. In order to quantify these differences in kinetics and extrapolate in vivo correlates of drug binding kinetics at DAT (i.e., apparent association and dissociation rates), we defined the 0-15 min window post i.p. injection as the "onset" of action and 20-60 min window as the "decline". The onset and decline segments of the time-course were evaluated using linear regression analysis of the rising and falling phases, respectively. As expected for a correlate of the association rate, the onset of action showed a clear dose-dependency for all the compounds (Figure 5e), with approx. 50 times steeper slope in the case of the S-aPVP compared to R-aPVP, and approx. 25 times steeper slope compared to cocaine (S-aPVP: slope $=106.2, p=0.015, F=65.96$; R-aPVP: slope $=2.608, p=0.0243, F=39.67$; cocaine: slope $=4.767, p=0.0231, F=41.72)$. By contrast, and consistent with the slow dissociation rates for aPVP enantiomers, the linear regression of the decline phase showed no dose-dependence or significance for the slopes of the enantiomers (S-aPVP: slope = $0.64, p=0.93, F=0.010$; R-aPVP: slope $=0.13, p=0.43, F=0.939$ ). For cocaine, a comparable linear regression revealed a dose-dependent and negative slope (cocaine: slope $=-1.042, p=0.03, F=29.86$ ). Therefore, our findings support a key role for binding kinetics at DAT in discriminating between the "slow kinetics" inhibitors S- and R-aPVP and the "fast kinetics" inhibitor cocaine.

\section{Discussion}

Inhibitors of DAT can elicit different behavioral phenomena in experimental animals and humans. Drugs more potently interacting with DAT are historically associated with abuse-liability (11), especially when 
showing better activity at DAT in comparison to SERT (53). Therefore, the preference for DAT over SERT, i.e. DAT/SERT selectivity ratio, is regularly used as a predictive indicator of drug addictive properties $(12,16)$. In agreement with previous studies $(18)$, we found that S-aPVP has a high DAT/SERT selectivity ratio when compared to both cocaine and R-aPVP, which suggests a higher abuse-liability. However, despite the fact that DAT/SERT selectivity has been proven to be an important indicator for the screening of drugs, several high affinity and DAT-selective inhibitors such as benztropines, rimcazole, GBR12909 and related analogs, do not induce the same reinforcing and stimulatory effects induced by cocaine $(15,54)$. The molecular basis for these differences is still not completely understood, and different hypotheses have been put forward (15).

In general, binding kinetics are suggested to play a role in the persistence of behavioral effects and in functional selectivity (55). Indeed, while the pharmacology of different compounds is normally assessed under thermodynamic equilibrium conditions, in the human body, the drug-target interaction is influenced by the constant flux of fluids and a variety of physiological processes. Hence, the in vivo properties differ from the in vitro thermodynamic equilibrium. Based on this idea, the kinetics of drug-target interactions, influenced both by association and dissociation rates $\left(k_{\text {on }}\right.$ and $k_{\text {off }}$ respectively) of the drug, have been suggested to play an important role in the pharmacological effect in vivo $(56,57)$. Consistently, binding kinetics have been exploited in the past to elucidate the affinity of antidepressants for the allosteric site of SERT (58). These studies recently led to the discovery of a SERT inhibitor with high affinity for its allosteric site (46). However, the role of binding kinetics in the effects mediated by DAT inhibitors is poorly explored and could potentially underly their heterogeneous pharmacological effects and have important consequences for drug development. As one example, the DAT-selective benztropine analog JHW007, can antagonize the cocaine-like reinforcing effects by slowly occupying DAT in the central nervous system (59), indicating that binding kinetics might shape the behavioral properties of DAT ligands. By contrast, a previous study found that S-aPVP engenders robust self-administration in rats, while R-aPVP is less effective in this regard (18). Therefore, establishing kinetic-activity relationships of DAT-ligands may help to (i) develop DAT-inhibitors devoid of addictive properties and (ii) define the impact of such kinetics in physiological and pharmacological processes.

Here, we compared the effects of the classical DAT inhibitor cocaine with the effects of aPVP enantiomers. In humans, aPVP displays a similar onset of action to cocaine but has more long-lasting effects, which may exacerbate the effects of aPVP intoxications $(20,60)$. Our systematic in vitro comparison of cocaine and the two enantiomers of aPVP highlighted substantial differences between the kinetic profiles at DAT, which could also be extended by observations in vivo as a significantly prolonged psychomotor effect in mice.

Our in vitro experiments indicated that the slow dissociation kinetics of aPVP enantiomers is likely not related to binding to an allosteric site, as shown for the SERT inhibitors S-Citalopram (61) and the more recent Lu AF60097 (46), but rather to the binding at orthosteric site. Indeed, we found that when the F76 of DAT is mutated to the corresponding residue in SERT (DAT-F76Y), the potency of aPVP enantiomers in inhibiting DA uptake is reduced, while no changes were observed for cocaine. Our docking data agree 
with previous studies, where the F76 in DAT, together with the corresponding Y95 in SERT are key residues for substrate recognition in the central binding site (62-64).

Our computational data shows that aPVP interacts with DAT in a manner similar to DA, amphetamines, and inhibitors like cocaine, RTI-55, or nisoxetine $(45,65)$. The binding pose of aPVP is also consistent with the experimental data summarized in Fig $2 \mathrm{~g}$ since $\mathrm{i}$ ) the V152I mutant lowers the $\mathrm{K}_{\mathrm{i}}$ of S-aPVP to DAT; ii) the binding pose suggests that the V152I mutation leads to an increase in hydrophobicity in the S1 and therefore enhances the interaction with the aromatic moiety of S-aPVP; iii) mutations of S149 and S429 to alanine had minimal effects on $\mathrm{K}_{\mathrm{i}}$, which is in line with the binding pose showing no direct contacts of these residues with S-aPVP; iv) the mutation F76Y introduces a possible additional hydrogen bond which cannot be used by S-aPVP since the required rotation would perturb its interaction with the S1.

We show that the non-competitive pharmacology of aPVP is secondary to DAT binding kinetics, since the non-competitive inhibition could be converted to a competitive profile by increasing the uptake time. This pharmacological profile is consistent with a pseudo-irreversible mechanism (47-49), and substantially differs from the one observed for the indole alkaloid ibogaine to SERT, which instead exhibits a noncompetitive pharmacology by stabilizing the inward-open conformation of SERT $(38,66,67)$. We speculate that the binding of aPVP in the central binding site may elicit local structural re-arrangements that are preventing its dissociation. A similar mechanism has been recently shown in the case of the $5-\mathrm{HT}_{2 \mathrm{~B}}$ receptor crystal structure in complex with LSD (68).

When examined in native tissue preparations, we observed differences in the relative potency of the drugs tested with uptake-inhibition experiments in HEK293 cells and synaptosomes showing S-aPVP $>$ Cocaine $>$ R-aPVP and the FSCV experiments showing instead S-aPVP > R-aPVP > cocaine. Considering that uptake-inhibition in both synaptosomal preparations and HEK293 cells drugs do not face any obstacle for binding to- and unbinding from their target, while in acute slices their target is embedded in the complex brain matrix which might affect these processes, we surmise that the differences in the relative potencies could be partially explained by their different kinetic selectivity (69), or by yet unestablished off-target effects.

Based on the in vitro studies, we tested if the differences in binding kinetics between the two aPVP enantiomers and cocaine might impact their psychomotor stimulant properties in mice. By conducting time-course experiments, we compared the onset of action and the decline of the effects elicited. We found that the differences in the $k_{\text {off }}$ are reflected in the prolonged in vivo effects of both S-and R-aPVP compared to cocaine. There were no differences in the decline of locomotor effects between the two enantiomers, but the enantiomers displayed much slower decline in comparison to cocaine. We surmise that the dose-dependency observed in the decline of action of cocaine is due to the short half-life of cocaine on DAT which makes it available for subsequent metabolism. In this scenario, increasing cocaine dose would also prolong its action by interfering with its metabolism. In contrast, the prolonged residence time of aPVP enantiomers at DAT would sequester the drug molecules on their target, reducing their availability for metabolic degradation. Importantly, the two enantiomers showed a very different onset of 
action which was also dose-dependent. It is noteworthy that we could not measure the $k_{\text {on }}$ of either enantiomer in vitro due to the practical limitations of our experimental methods, but the difference in the onset of action, interpreted as apparent association, can justify their different equilibrium affinities. Indeed, considering that the two enantiomers show 100 -fold difference in their equilibrium potency at DAT and almost identical dissociation rates, the 50 -fold difference their onset of action, and therefore in their apparent association rates, would be sufficient to justify their different equilibrium differences and overall in vivo potency. Thus, we conclude that while cocaine and aPVP differ mainly in their dissociation rates, S- and R-aPVP differ uniquely in their association rates. This is consistent with previous observations showing that the enantioselectivity of different compounds for their target is mainly driven by their $k_{\text {on }}(57)$.

It has been shown previously that the reinforcing effects mediated by aPVP both in monkeys and rats are substantially prolonged when compared to effects of cocaine $(26,70)$. aPVP enantiomers show striking differences in binding kinetics when compared to cocaine which are in line with the kinetics of our behavioral experiments. These facts highlight the possibility of complex heterogeneity among different psychostimulants with pharmacokinetics and binding kinetics differentially shaping their pharmacological profile and effects.

The pseudo-irreversible kinetics observed in the case of aPVP enantiomers at DAT has important consequences not only in the understanding of psychostimulant effects elicited by aPVP but also in its wide-spread side effects such as delirium states, cardiovascular, and renal complications $(20,60)$. In this study we have focused on the pharmacology of aPVP enantiomers at DAT because of its well-established role of DAT in psychomotor functions (4). However, considering the role of norepinephrine and NET in the regulation of blood pressure and heart rate (71), the structural similarities between DAT and NET (1), and the high affinity that aPVP has for NET as well (18), we surmise that a slow dissociation rate at NET might underly the peripheral side effects commonly observed in aPVP users. A prolonged NET inhibition could indeed dramatically impact the cardiovascular system due to the role of norepinephrine in the regulation of blood pressure and heart rate (71). In agreement, administration of aPVP-enantiomers in rats shows an extended increase in blood-pressure (18). However, it is important to consider that DAT, in addition to its important role in the brain, is also widely expressed peripherally (72). Prolonged inhibition of the peripheral DAT could therefore, in principle, result in a peripheral hyperdopaminergic state, consequently altering systemic blood pressure (73). A more systematic analysis focusing on the peripheral effects of aPVP will be required to further elucidate the molecular targets leading to possibly detrimental side effects.

Future studies should compare different DAT-inhibitors in terms of their detailed kinetic-activity relationships. For example, two other high affinity DAT inhibitors, GBR12909 and the aPVP-analog 3,4methylenedioxypyrovalerone (MDPV), show long residence time at DAT based on slow DA clearance in FSCV experiments $(74,75)$. As far as we are aware, binding kinetics at DAT have not been investigated for MDPV, but this drug is associated with sustained stimulatory effects in experimental animals (75). Our 
results on aPVP are in line with the binding kinetics suggested in case of MDPV and highlight the need for a thorough structure-kinetic relationship study at DAT.

In conclusion, we show that drug binding kinetics at DAT can have a significant impact on the psychomotor stimulant effects of drugs in vivo. Given this information, a more detailed assessment of drug-binding kinetics for DAT inhibitors might provide insights for the design of novel DAT inhibitors with improved clinical utility. Furthermore, it shows how psychopharmacological research on illicit drugs may help to reach a better understanding of physiological and toxicological processes.

\section{Declarations}

\section{Acknowledgements}

The authors acknowledge Michael Freissmuth for data discussion and the NIDA drug supply program for supplying a-PVP. This work was supported by the Austrian Science Fund/FWF, grant W1232 (MolTag) to HHS, the FWF project P32017 to TS, the Theodor Körner Fonds 2020 to JM and the Intramural Research Program of the National Institute on Drug Abuse, National Institutes of Health, grant DA 000522-13 to MHB.

\section{Conflict of Interest}

All authors declare that there is no financial conflict of interest associated with the current manuscript.

\section{Data availability}

Supplementary information is available at MP's website

\section{References}

1. Kristensen AS, Andersen J, Jørgensen TN, Sørensen L, Eriksen J, Loland CJ, et al. SLC6 neurotransmitter transporters: structure, function, and regulation. Pharmacol Rev. 2011 Sep 1;63(3):585640. 10.1124/pr.108.000869

2. Kilty JE, Lorang D, Amara SG. Cloning and expression of a cocaine-sensitive rat dopamine transporter. Science (80- ). 1991;254(5031):578-9. 10.1126/science.1948035

3. Shimada S, Kitayama S, Lin CL, Patel A, Nanthakumar E, Gregor P, et al. Cloning and expression of a cocaine-sensitive dopamine transporter complementary DNA. Science (80- ). 1991;254(5031):576-8. 10.1126/science.1948034 
4. Giros B, Jaber M, Jones SR, Wightman RM, Caron MG. Hyperlocomotion and indifference to cocaine and amphetamine in mice lacking the dopamine transporter. Nature. 1996;379(6566):606-12. $10.1038 / 379606 a 0$

5. Penmatsa A, Wang KH, Gouaux E. X-ray structure of dopamine transporter elucidates antidepressant mechanism. Nature. 2013 Nov 15;503(7474):85-90. 10.1038/nature12533

6. Leo D, Sukhanov I, Zoratto F, Illiano P, Caffino L, Sanna F, et al. Pronounced hyperactivity, cognitive dysfunctions, and BDNF dysregulation in dopamine transporter knock-out rats. J Neurosci. 2018 Feb 21;38(8):1959-72. 10.1523/JNEUROSCI.1931-17.2018

7. Mazei-Robison MS, Bowton E, Holy M, Schmudermaier M, Freissmuth M, Sitte HH, et al. Anomalous dopamine release associated with a human dopamine transporter coding variant. J Neurosci. $2008 \mathrm{Jul}$ 9;28(28):7040-6. 10.1523/JNEUROSCI.0473-08.2008

8. Hansen FH, Skjørringe T, Yasmeen S, Arends N V., Sahai MA, Erreger K, et al. Missense dopamine transporter mutations associate with adult parkinsonism and ADHD. J Clin Invest. 2014 Jul 1;124(7):3107-20. 10.1172/JCI73778

9. Bhat S, El-Kasaby A, Freissmuth M, Sucic S. Functional and Biochemical Consequences of Disease Variants in Neurotransmitter Transporters: A Special Emphasis on Folding and Trafficking Deficits. Pharmacol Ther. 2021 Jun 1;222. 10.1016/j.pharmthera.2020.107785

10. Sitte HH, Freissmuth M. Amphetamines, new psychoactive drugs and the monoamine transporter cycle. Trends Pharmacol Sci. 2015;36(1):41-50. 10.1016/j.tips.2014.11.006

11. Ritz MC, Lamb RJ, Goldberg SR, Kuhar MJ. Cocaine receptors on dopamine transporters are related to self-administration of cocaine. Science (80-). 1987 Sep 4;237(4819):1219-23.

10.1126/science. 2820058

12. Bauer $\mathrm{C}$, Banks $\mathrm{M}$, Blough $\mathrm{B}$, Negus $\mathrm{S}$. Use of intracranial self-stimulation to evaluate abuse-related and abuse-limiting effects of monoamine releasers in rats. Br J Pharmacol. 2013 Feb;168(4):850-62. 10.1111/j.1476-5381.2012.02214.x

13. Rothman RB, Partilla JS, Baumann MH, Lightfoot-Siordia C, Blough BE. Studies of the Biogenic Amine Transporters. 14. Identification of Low-Efficacy "Partial" Substrates for the Biogenic Amine Transporters. J Pharmacol Exp Ther. 2012;341(1):251-62. 10.1124/jpet.111.188946

14. Niello M, Gradisch R, Loland CJ, Stockner T, Sitte HH. Allosteric Modulation of Neurotransmitter Transporters as a Therapeutic Strategy. Trends Pharmacol Sci. 2020 May;41(7):446-63. 10.1016/j.tips.2020.04.006

15. Reith MEA, Blough BE, Hong WC, Jones KT, Schmitt KC, Baumann MH, et al. Behavioral, biological, and chemical perspectives on atypical agents targeting the dopamine transporter. Drug Alcohol Depend. 
2015;147:1-19. 10.1016/j.drugalcdep.2014.12.005

16. Luethi D, Liechti ME. Designer drugs: mechanism of action and adverse effects. Arch Toxicol. 2020 Apr 6;94(4):1085-133. 10.1007/s00204-020-02693-7

17. Baumann MH, Walters HM, Niello M, Sitte HH. Neuropharmacology of synthetic cathinones. In: Handbook of Experimental Pharmacology. Springer New York LLC; 2018. p. 113-42.

10.1007/164_2018_178

18. Schindler CW, Thorndike EB, Walters HM, Walther D, Rice KC, Baumann MH. Stereoselective neurochemical, behavioral, and cardiovascular effects of a-pyrrolidinovalerophenone enantiomers in male rats. Addict Biol. 2020 Nov 13;25(6). 10.1111/adb.12842

19. Maier J, Rauter L, Rudin D, Niello M, Holy M, Schmid D, et al. a-PPP and its derivatives are selective partial releasers at the human norepinephrine transporter. Neuropharmacology. 2021 Jun;190:108570. 10.1016/j.neuropharm.2021.108570

20. Patocka J, Zhao B, Wu W, Klimova B, Valis M, Nepovimova E, et al. Flakka: New Dangerous Synthetic Cathinone on the Drug Scene. Int J Mol Sci. 2020 Oct 31;21(21). 10.3390/ijms21218185

21. Karila L, Lafaye G, Scocard A, Cottencin O, Benyamina A. MDPV and a-PVP use in humans: The twisted sisters. Neuropharmacology. 2018 May 15;134(Pt A):65-72. 10.1016/j.neuropharm.2017.10.007

22. Umebachi R, Aoki H, Sugita M, Taira T, Wakai S, Saito T, et al. Clinical characteristics of apyrrolidinovalerophenone (a-PVP) poisoning. Clin Toxicol. 2016 Aug 8;54(7):563-7.

10.3109/15563650.2016.1166508

23. Crespi C. Flakka-Induced Prolonged Psychosis. Case Rep Psychiatry. 2016;2016:1-2.

$10.1155 / 2016 / 3460849$

24. Volkow ND, Ding YS, Fowler JS, Wang GJ, Logan J, Gatley JS, et al. Is Methylphenidate Like Cocaine?: Studies on Their Pharmacokinetics and Distribution in the Human Brain. Arch Gen Psychiatry. 1995;52(6):456-63. 10.1001/archpsyc.1995.03950180042006

25. Inaba T. Cocaine: Pharmacokinetics and biotransformation in man. Can J Physiol Pharmacol. 1989;67(9):1154-7. 10.1139/y89-184

26. Gannon BM, Baumann MH, Walther D, Jimenez-Morigosa C, Sulima A, Rice KC, et al. The abuserelated effects of pyrrolidine-containing cathinones are related to their potency and selectivity to inhibit the dopamine transporter. Neuropsychopharmacology. 2018 Nov 1;43(12):2399-407. 10.1038/s41386018-0209-3

27. Gannon BM, Galindo KI, Mesmin MP, Sulima A, Rice KC, Collins GT. Relative reinforcing effects of second-generation synthetic cathinones: Acquisition of self-administration and fixed ratio dose-response 
curves in rats. Neuropharmacology. 2018 May 15;134(Pt A):28-35. 10.1016/j.neuropharm.2017.08.018

28. Duart-Castells L, Nadal-Gratacós N, Muralter M, Puster B, Berzosa X, Estrada-Tejedor R, et al. Role of amino terminal substitutions in the pharmacological, rewarding and psychostimulant profiles of novel synthetic cathinones. Neuropharmacology. 2021 Mar;186:108475. 10.1016/j.neuropharm.2021.108475

29. Gatch MB, Dolan SB, Forster MJ. Comparative behavioral pharmacology of three pyrrolidinecontaining synthetic cathinone derivatives. J Pharmacol Exp Ther. 2015 Aug 1;354(2):103-10. 10.1124/jpet.115.223586

30. H. Brooks W, C. Guida W, G. Daniel K. The Significance of Chirality in Drug Design and Development. Curr Top Med Chem. 2011 Mar 28;11(7):760-70. 10.2174/156802611795165098

31. Gregg RA, Baumann MH, Partilla JS, Bonano JS, Vouga A, Tallarida CS, et al. Stereochemistry of mephedrone neuropharmacology: Enantiomer-specific behavioural and neurochemical effects in rats. $\mathrm{Br}$ J Pharmacol. 2015 Feb 1;172(3):883-94. 10.1111/bph.12951

32. Mayer FP, Cintulova D, Pittrich DA, Wimmer L, Luethi D, Holy M, et al. Stereochemistry of phase-1 metabolites of mephedrone determines their effectiveness as releasers at the serotonin transporter. Neuropharmacology. 2019 Apr 1;148:199-209. 10.1016/j.neuropharm.2018.12.032

33. Niello M, Cintulová D, Raithmayr P, Holy M, Jäntsch K, Colas C, et al. Effects of Hydroxylated Mephedrone Metabolites on Monoamine Transporter Activity in vitro. Front Pharmacol. 2021 Apr 9;12. 10.3389/fphar.2021.654061

34. Philogene-Khalid HL, Hicks C, Reitz AB, Liu-Chen L-Y, Rawls SM. Synthetic cathinones and stereochemistry: $S$ enantiomer of mephedrone reduces anxiety- and depressant-like effects in cocaine- or MDPV-abstinent rats. Drug Alcohol Depend. 2017;178:119-25. 10.1016/j.drugalcdep.2017.04.024

35. Mayer FP, Luf A, Nagy C, Holy M, Schmid R, Freissmuth M, et al. Application of a combined approach to identify new psychoactive street drugs and decipher their mechanisms at monoamine transporters. In: Current Topics in Behavioral Neurosciences. 2016. p. 333-50. 10.1007/7854_2016_63

36. Niello M, Cintulova D, Hellsberg E, Jäntsch K, Holy M, Ayatollahi LH, et al. para-Trifluoromethylmethcathinone is an allosteric modulator of the serotonin transporter. Neuropharmacology. $2019 \mathrm{Apr}$ 24;161:107615. 10.1016/j.neuropharm.2019.04.021

37. Sitte HH, Huck S, Reither H, Boehm S, Singer EA, Pifl C. Carrier-mediated release, transport rates, and charge transfer induced by amphetamine, tyramine, and dopamine in mammalian cells transfected with the human dopamine transporter. J Neurochem. 1998 Nov 13;71(3):1289-97. 10.1046/j.14714159.1998.71031289.x

38. Bulling S, Schicker K, Zhang YW, Steinkellner T, Stockner T, Gruber CW, et al. The mechanistic basis for noncompetitive ibogaine inhibition of serotonin and dopamine transporters. J Biol Chem. 
39. Hasenhuetl PS, Bhat S, Mayer FP, Sitte HH, Freissmuth M, Sandtner W. A kinetic account for amphetamine-induced monoamine release. J Gen Physiol. 2018 Feb 9;150(3):431-51.

10.1085/jgp.201711915

40. Hoffman AF, Spivak CE, Lupica CR. Enhanced dopamine release by dopamine transport inhibitors described by a restricted diffusion model and fast-scan cyclic voltammetry. ACS Chem Neurosci. 2016;7(6):700-9. 10.1021/acschemneuro.5b00277

41. Steinkellner T, Mus L, Eisenrauch B, Constantinescu A, Leo D, Konrad L, et al. In Vivo Amphetamine Action is Contingent on aCaMKII. Neuropsychopharmacology. 2014 Oct 29;39(11):2681-93.

$10.1038 /$ npp. 2014.124

42. Gabriel MO, Nikou M, Akinola OB, Pollak DD, Sideromenos S. Western diet-induced fear memory impairment is attenuated by 6-shogaol in C57BL/6N mice. Behav Brain Res. 2020 Feb 17;380.

10.1016/j.bbr.2019.112419

43. Krueger BK. Kinetics and Block of Dopamine Uptake in Synaptosomes from Rat Caudate Nucleus. J Neurochem. 1990;55(1):260-7. 10.1111/j.1471-4159.1990.tb08847.x

44. Beuming T, Kniazeff J, Bergmann ML, Shi L, Gracia L, Raniszewska K, et al. The binding sites for cocaine and dopamine in the dopamine transporter overlap. Nat Neurosci. 2008 Jul 22;11(7):780-9. $10.1038 / \mathrm{nn} .2146$

45. Wang $\mathrm{KH}$, Penmatsa A, Gouaux E. Neurotransmitter and psychostimulant recognition by the dopamine transporter. Nature. 2015;521(7552):322-7. 10.1038/nature14431

46. Plenge P, Abramyan AM, Sørensen G, Mørk A, Weikop P, Gether U, et al. The mechanism of a highaffinity allosteric inhibitor of the serotonin transporter. Nat Commun. 2020 Dec 20;11(1):1491. 10.1038/s41467-020-15292-y

47. Rang HP. The kinetics of action of acetylcholine antagonists in smooth muscle. Proc R Soc Lond B Biol Sci. 1966;164(996):488-510. 10.1098/rspb.1966.0045

48. Kenakin T. Overview of receptor interactions of agonists and antagonists. In: Current Protocols in Pharmacology. Curr Protoc Pharmacol; 2008. 10.1002/0471141755.ph0401s42

49. Lew MJ, Ziogas J, Christopoulos A. Dynamic mechanisms of non-classical antagonism by competitive AT1 receptor antagonists. Trends Pharmacol Sci. 2000 Oct 1;21(10):376-81. 10.1016/S0165-6147(00)01523-6

50. Hasenhuetl PS, Schicker K, Koenig X, Li Y, Sarker S, Stockner T, et al. Ligand Selectivity among the Dopamine and Serotonin Transporters Specified by the Forward Binding Reaction. Mol Pharmacol. 2015 
May 18;88(1):12-8. 10.1124/mol.115.099036

51. Erreger K, Grewer C, Javitch JA, Galli A. Currents in response to rapid concentration jumps of amphetamine uncover novel aspects of human dopamine transporter function. J Neurosci. $2008 \mathrm{Jan}$ 23;28(4):976-89. 10.1523/JNEUROSCI.2796-07.2008

52. Li Y, Mayer FP, Hasenhuetl PS, Burtscher V, Schicker K, Sitte HH, et al. Occupancy of the zincbinding site by transition metals decreases the substrate affinity of the human dopamine transporter by an allosteric mechanism. J Biol Chem. 2017 Apr 28;292(10):4235-43. 10.1074/jbc.M116.760140

53. Wee S, Anderson KG, Baumann MH, Rothman RB, Blough BE, Woolverton WL. Relationship between the serotonergic activity and reinforcing effects of a series of amphetamine analogs. $J$ Pharmacol Exp Ther. 2005 May 17;313(2):848-54. 10.1124/jpet.104.080101

54. Newman AH, Kulkarni S. Probes for the dopamine transporter: New leads toward a cocaine-abuse therapeutic - A focus on analogues of benztropine and rimcazole. Med Res Rev. 2002 Sep;22(5):429-64. 10.1002/med.10014

55. Copeland RA. The drug-target residence time model: A 10-year retrospective. Nat Rev Drug Discov. 2016 Feb 3;15(2):87-95. 10.1038/nrd.2015.18

56. Copeland RA, Pompliano DL, Meek TD. Drug-target residence time and its implications for lead optimization. Nat Rev Drug Discov. 2006;5(9):730-9. 10.1038/nrd2082

57. IJzerman AP, Guo D. Drug-Target Association Kinetics in Drug Discovery. Vol. 44, Trends in Biochemical Sciences. Elsevier Ltd; 2019. p. 861-71. 10.1016/j.tibs.2019.04.004

58. Plenge P, Mellerup ET. An affinity-modulating site on neuronal monoamine transport proteins. Pharmacol Toxicol. 1997 Apr;80(4):197-201.

59. Desai RI, Kopajtic TA, Koffarnus M, Newman AH, Katz JL. Identification of a dopamine transporter ligand that blocks the stimulant effects of cocaine. J Neurosci. 2005 Feb 23;25(8):1889-93. 10.1523/JNEUROSCI.4778-04.2005

60. Nóbrega L, Dinis-Oliveira RJ. The synthetic cathinone a-pyrrolidinovalerophenone (a-PVP): pharmacokinetic and pharmacodynamic clinical and forensic aspects. Drug Metab Rev. $2018 \mathrm{Apr}$ 3;50(2):125-39. 10.1080/03602532.2018.1448867

61. Coleman JA, Green EM, Gouaux E. X-ray structures and mechanism of the human serotonin transporter. Nature. 2016;532(7599):334-9. 10.1038/nature17629

62. Larsen MB, Sonders MS, Mortensen O V., Larson GA, Zahniser NR, Amara SG. Dopamine Transport by the Serotonin Transporter: A Mechanistically Distinct Mode of Substrate Translocation. J Neurosci. 2011;31(17):6605-15. 10.1523/JNEUROSCI.0576-11.2011 
63. Grouleff J, Ladefoged LK, Kolds $\varnothing \mathrm{H}$, Schiøtt B. Monoamine transporters: Insights from molecular dynamics simulations. Front Pharmacol. 2015;6(OCT). 10.3389/fphar.2015.00235

64. Cheng $\mathrm{MH}$, Bahar I. Monoamine transporters: structure, intrinsic dynamics and allosteric regulation. Nat Struct Mol Biol. 2019 Jul 3;26(7):545-56. 10.1038/s41594-019-0253-7

65. Penmatsa A, Wang KH, Gouaux E. X-ray structures of Drosophila dopamine transporter in complex with nisoxetine and reboxetine. Nat Struct Mol Biol. 2015 Jun 3;22(6):506-8. 10.1038/nsmb.3029

66. Jacobs MT, Zhang YW, Campbell SD, Rudnick G. Ibogaine, a noncompetitive inhibitor of serotonin transport, acts by stabilizing the cytoplasm-facing state of the transporter. J Biol Chem. 2007 Oct 5;282(40):29441-7. 10.1074/jbc.M704456200

67. Coleman JA, Yang D, Zhao Z, Wen PC, Yoshioka C, Tajkhorshid E, et al. Serotonin transporteribogaine complexes illuminate mechanisms of inhibition and transport. Nature. 2019 May 24;569(7754):141-5. 10.1038/s41586-019-1135-1

68. Wacker D, Wang S, McCorvy JD, Betz RM, Venkatakrishnan AJ, Levit A, et al. Crystal Structure of an LSD-Bound Human Serotonin Receptor. Cell. 2017 Jan 26;168(3):377-389.e12.

10.1016/j.cell.2016.12.033

69. Tonge PJ. Drug-Target Kinetics in Drug Discovery. ACS Chem Neurosci. 2018 Jan 17;9(1):29-39. 10.1021/acschemneuro.7b00185

70. Collins GT, Sulima A, Rice KC, France CP. Self-administration of the synthetic cathinones 3,4methylenedioxypyrovalerone (MDPV) and a-pyrrolidinopentiophenone (a-PVP) in rhesus monkeys. Psychopharmacology (Berl). 2019 Dec 1;236(12):3677-85. 10.1007/s00213-019-05339-4

71. Schroeder C, Jordan J. Norepinephrine transporter function and human cardiovascular disease. Am J Physiol - Hear Circ Physiol. 2012 Dec 1;303(11). 10.1152/ajpheart.00492.2012

72. Mackie P, Lebowitz J, Saadatpour L, Nickoloff E, Gaskill P, Khoshbouei H. The dopamine transporter: An unrecognized nexus for dysfunctional peripheral immunity and signaling in Parkinson's Disease. Brain Behav Immun. 2018 May 1;70:21-35. 10.1016/j.bbi.2018.03.020

73. Harris RC, Zhang MZ. Dopamine, the kidney, and hypertension. Curr Hypertens Rep. 2012 Apr;14(2):138-43. 10.1007/s11906-012-0253-Z

74. Bull DR, Palij P, Sheehan MJ, Millar J, Stamford JA, Kruk ZL, et al. Application of fast cyclic voltammetry to measurement of electrically evoked dopamine overflow from brain slices in vitro. $J$ Neurosci Methods. 1990;32(1):37-44. 10.1016/0165-0270(90)90069-R

75. Baumann MH, Partilla JS, Lehner KR, Thorndike EB, Hoffman AF, Holy M, et al. Powerful cocainelike actions of 3,4-methylenedioxypyrovalerone (MDPV), a principal constituent of psychoactive "bath 


\section{Figures}

a

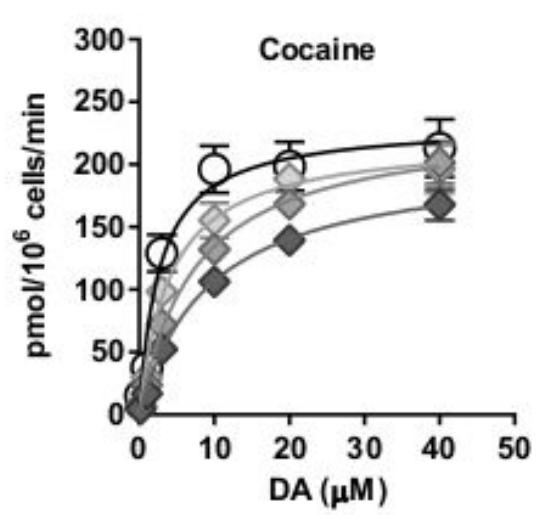

d

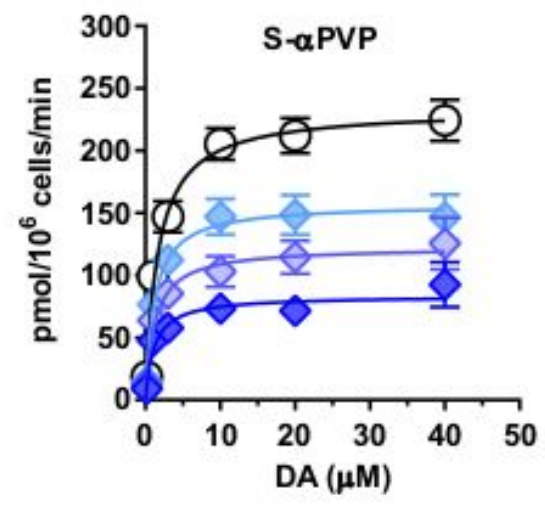

g

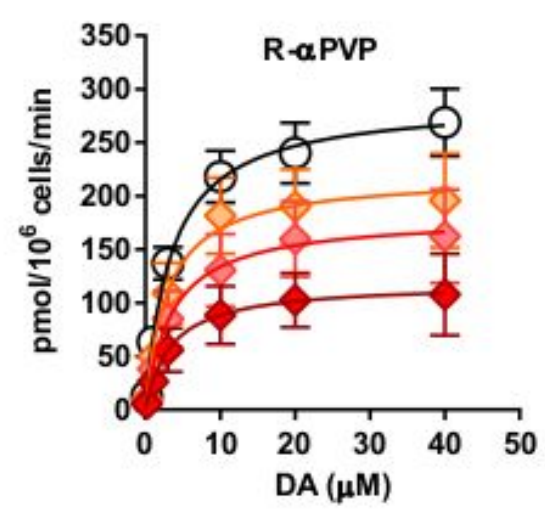

b

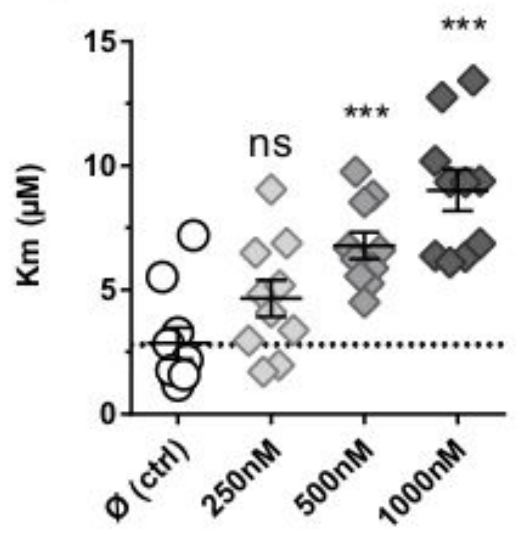

e

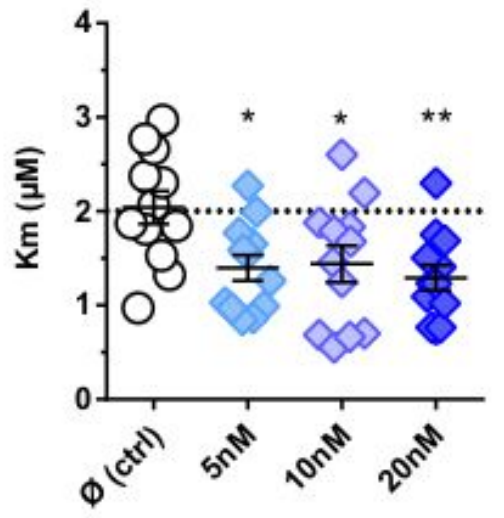

h

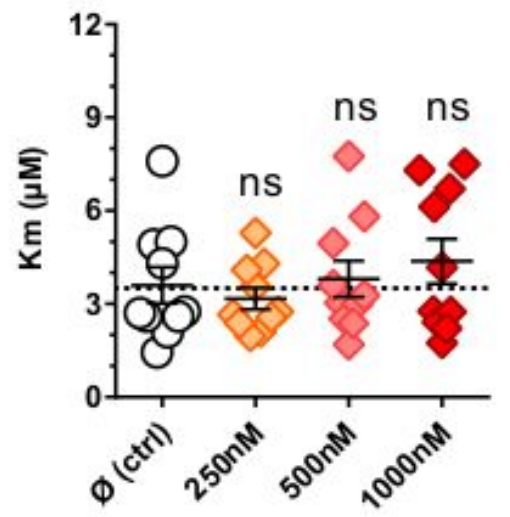

C

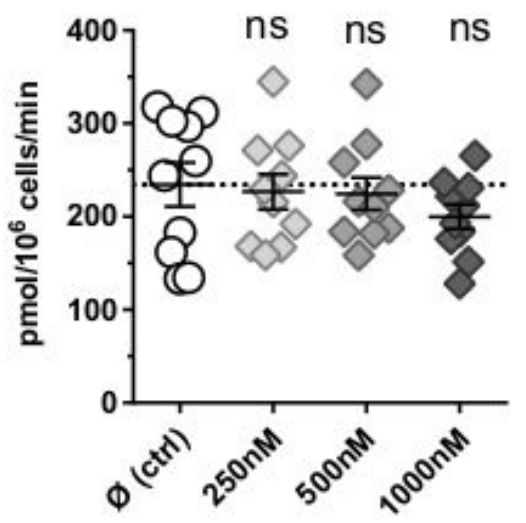

f

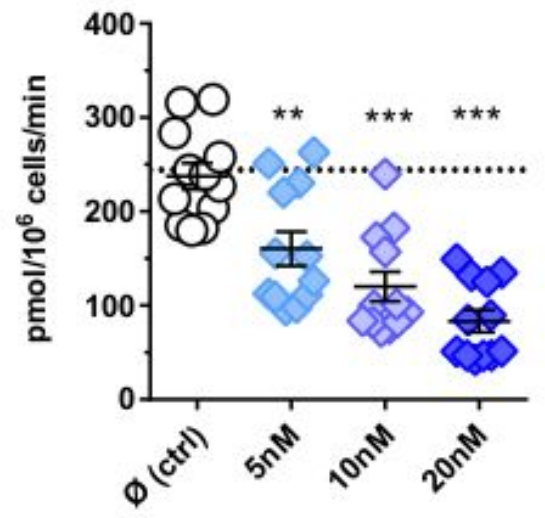

i

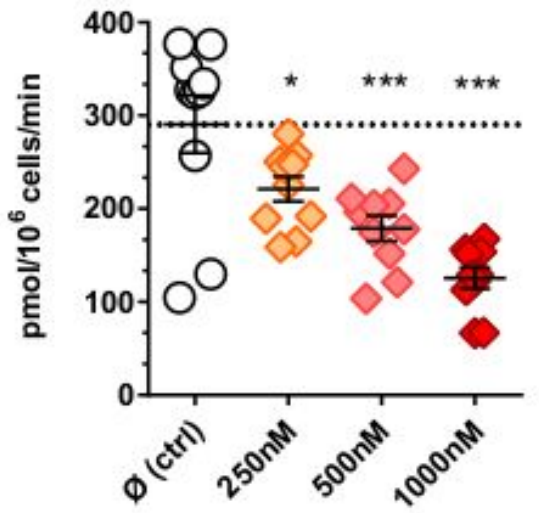

Figure 1 
Non-competitive inhibition of aPVP enantiomers. a) Saturation of DA uptake conducted in presence of cocaine 250nM (light grey), 500nM (grey) or 1000nM (dark grey). b) Cocaine increases $\mathrm{Km}$ in dosedependent manner but c) does not decrease Vmax. d) Saturation of DA uptake conducted in presence of S-aPVP 5nM (turquoise), 10nM (light blue) or 20nM (dark blue). e) aPVP does not drastically change the $\mathrm{km}$, but f) reduces Vmax dose-dependently. g) Saturation of DA uptake conducted in presence of R-aPVP 250nM (orange), 500nM (light red) or 1000nM (dark red). h) R-aPVP does not drastically change the km, but i) reduces Vmax dose-dependently. Data is shown as mean $\pm S E M$ of at least 5 independent experiments conducted in duplicates. Statistics is conducted with One-way ANOVA followed by Dunnet's post-hoc multiple comparison vs control $(\varnothing) .{ }^{* *}=p<0.01$, ${ }^{* * \star} p<0.001,{ }^{* * * *} p<0.0001$.

\section{a Competitive}
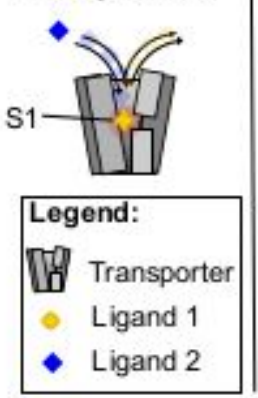

Non-competitive

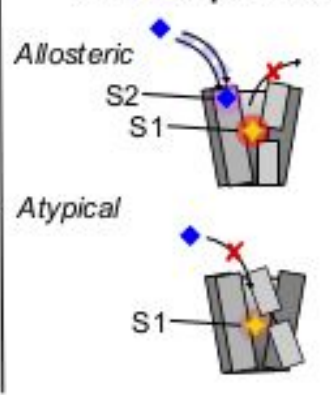

b

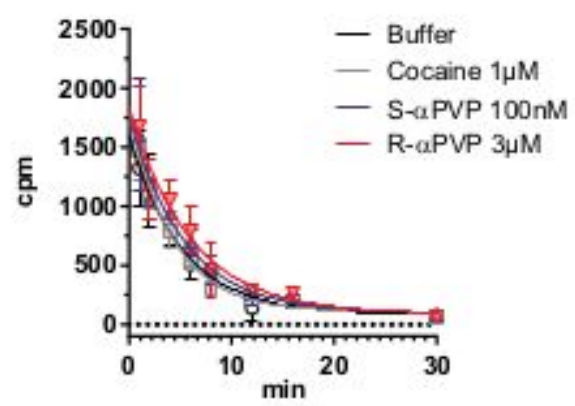

e

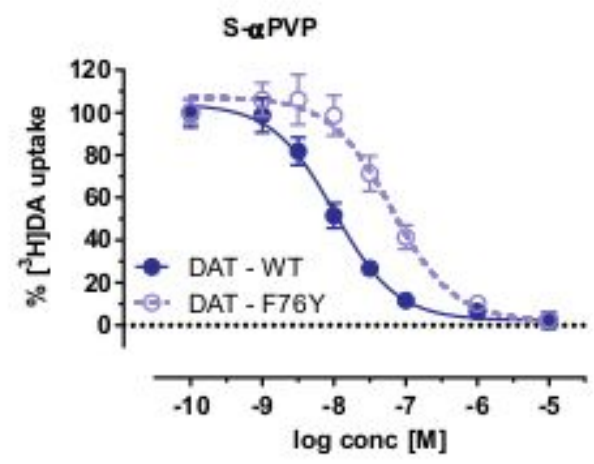

h

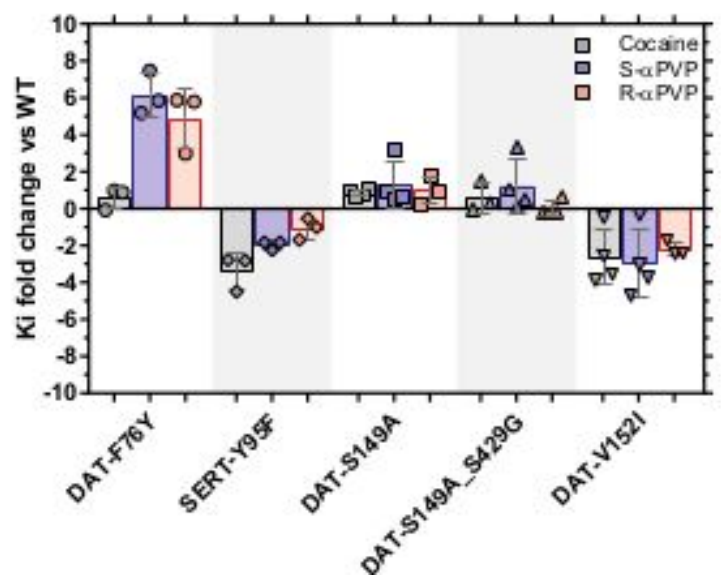

c

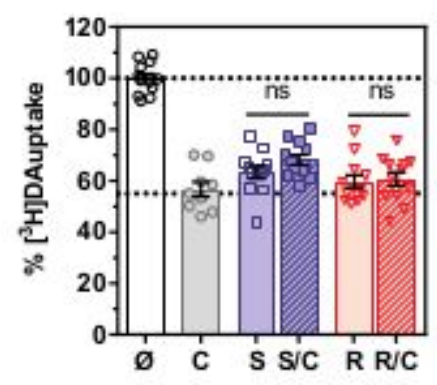

f

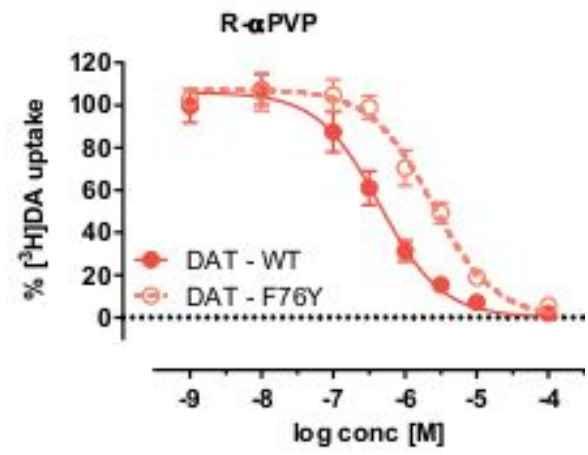

i

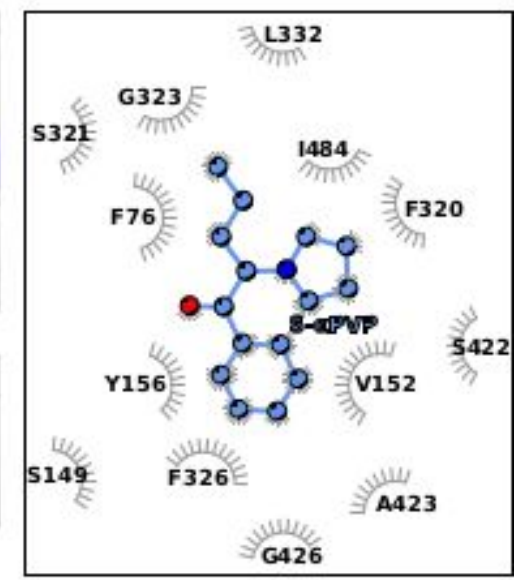




\section{Figure 2}

Cocaine and aPVP enantiomers binding mode in DAT. a) Mechanism of action of competitive, and noncompetitive (allosteric vs atypical) inhibition. b) Dissociation of [3H]WIN35428 in DAT membranes. The experiments were conducted at $4^{\circ} \mathrm{C}$. Data are mean $\pm S E M n \geq 3$ independent experiments conducted in duplicates. c) Single-point uptake inhibition of $0.2 \mu \mathrm{M}[3 \mathrm{H}] \mathrm{DA}$ conducted in HEK293cells stably expressing DAT. Compounds are pre-incubated at their IC50 alone or in combinations $(\varnothing=$ control, untreated; $C=$ cocaine 100nM; S=S-aPVP 10nM; S/C= cocaine 100nM+S-aPVP 10nM; R= R-aPVP 300nM; R/C= R-aPVP 300nM+cocaine 100nM). One-Way ANOVA followed by Dunnett's Multiple Comparison Test vs Cocaine ${ }^{*}=p<0.05,{ }^{* *}=p<0.01,{ }^{* * *}=p<0.001$. c-e) DAT-WT and DAT-F76Y uptake-inhibition profiles for Cocaine, SaPVP and R-aPVP. g) Site-directed mutagenesis of DAT orthosteric binding site. DAT residues are mutated in the corresponding residue in SERT. Data are shown as Ki fold change compared to wild-type DAT (mean $\pm S D)$. Every symbol represents an individual experiment conducted in triplicate. h) Membrane and front view of the S1 of the human DAT showing the best docking pose of S-aPVP (blue). TM10 and TM11 are not shown for clarity, while residues F76, S149, V152, and S429 are highlighted as sticks and coloured by atom type. The two sodium ions are represented as dark blue spheres. i) 2D interaction map of S-aPVP with the human DAT according to the binding mode shown in panel $\mathrm{h}$. 
a

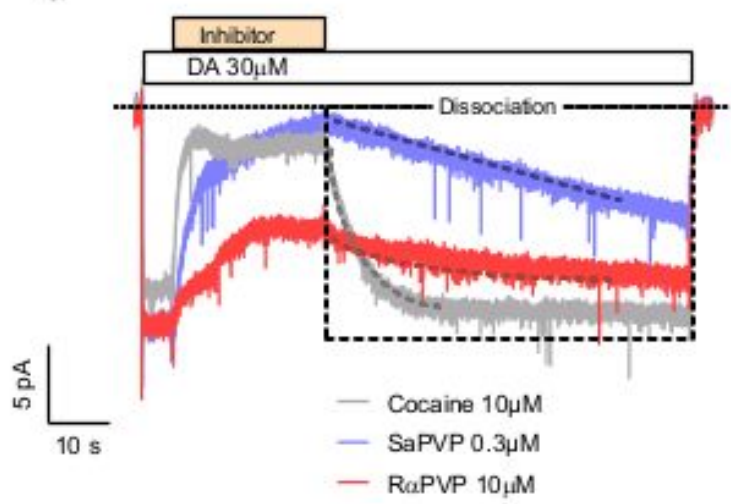

d

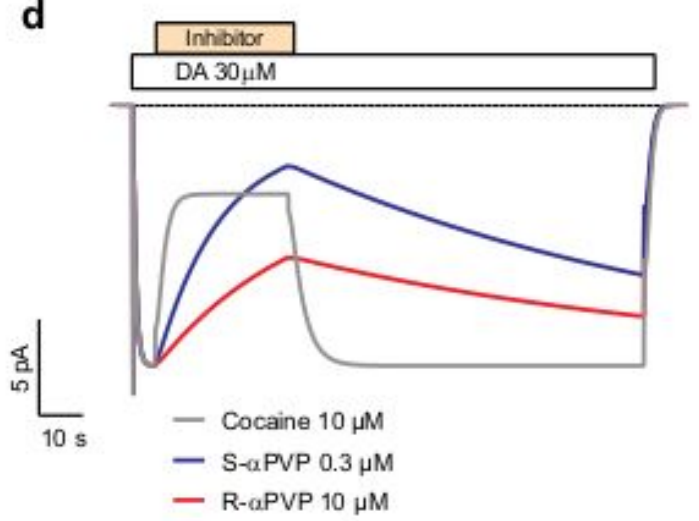

g

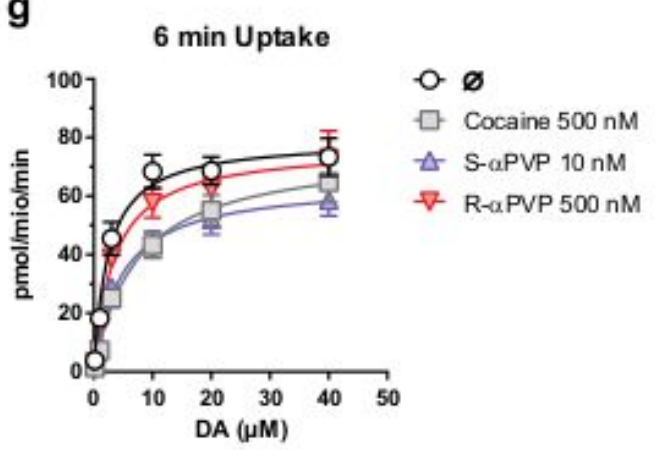

b
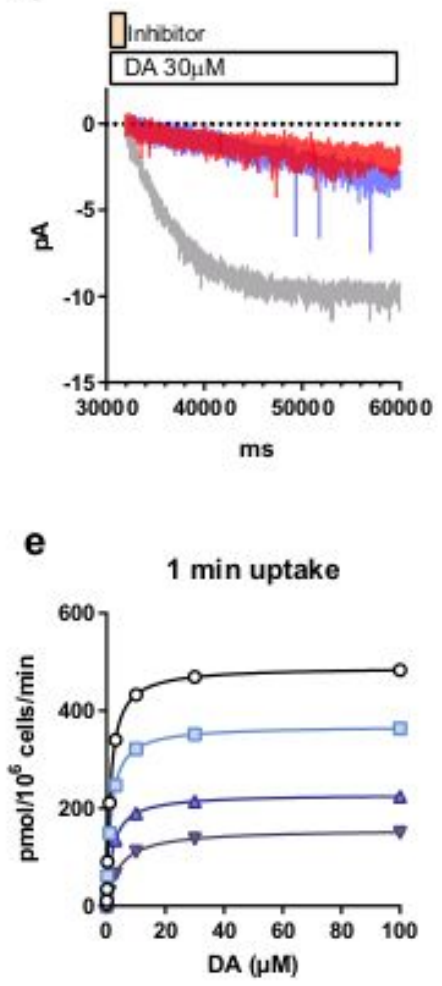

h

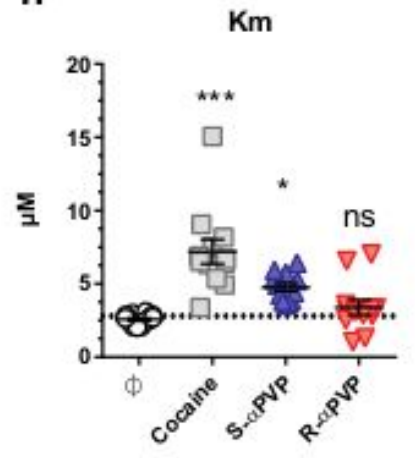

C

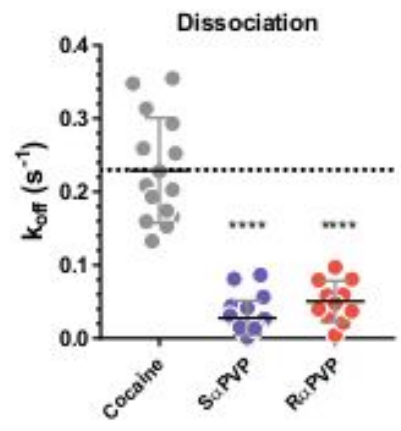

f

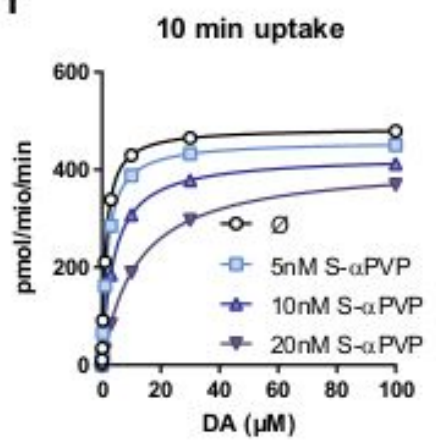

i

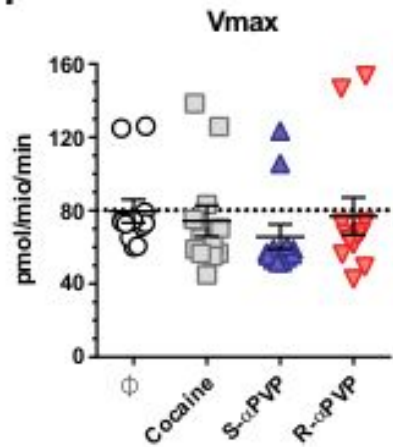

Figure 3

Binding kinetics of Cocaine and APVP enantiomers at DAT. a) Representative trace and protocol employed for the measurement. DA application is highlighted by the white box, while the inhibitor application is highlighted by the yellow box. Dashed boxes indicate the part of the traces used for extrapolated the dissociation rates, with the dashed colored lines represent the non-linear regression fit used to extrapolate rates from the traces. b) magnified and corrected representative trace extrapolated from the dashed rectangle in panel a), highlighting the differences in the dissociation rates between the three inhibitors. c) quantification of the dissociation rates between cocaine (grey), S-aPVP (blue) and RaPVP (red). DATA are mean \pm SEM of at least 10 cells. d) representative trace of the synthetic currents obtained from the kinetic model. e) Modelled saturation of uptake experiment in presence of S-aPVP and 1 min of DA uptake and f) 10 min of uptake. g) saturation of [3H]DA uptake conducted in HEK293 
transiently expressing DAT in presence of the indicated concentration of the inhibitor. h) Km change due to the inhibitor pre-incubation when the uptake time is extended to $6 \mathrm{~min}$. i) Vmax is not altered by any of the inhibitors when the uptake time is extended to $6 \mathrm{~min}$.
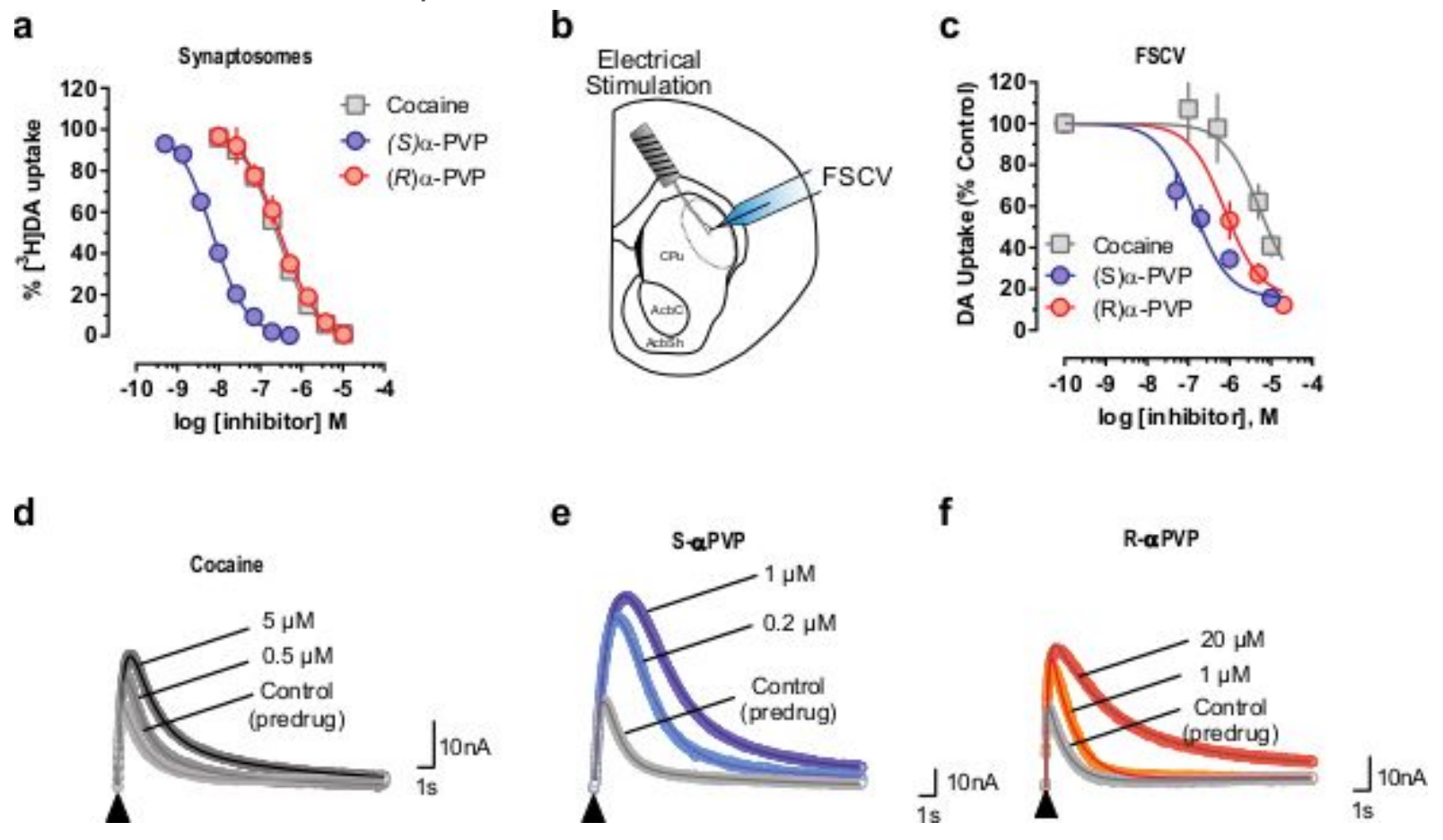

Figure 4

FSCV in acute striatal slices. a) Uptake-inhibition in rat striatal synaptosomes b) schematic of the FSCV experiments with the placement of recording and stimulating electrode in the dorsal striatum. c) Uptakeinhibition during FSCV experiments and $d-f$ ) representative traces of FSCV recordings in the presence of cocaine (left), S-aPVP (middle) and R-aPVP (right). DA release is elicited by electrical stimulation delivered as indicated by the black triangle. The control trace (predrug) is always indicated in light grey. 
a

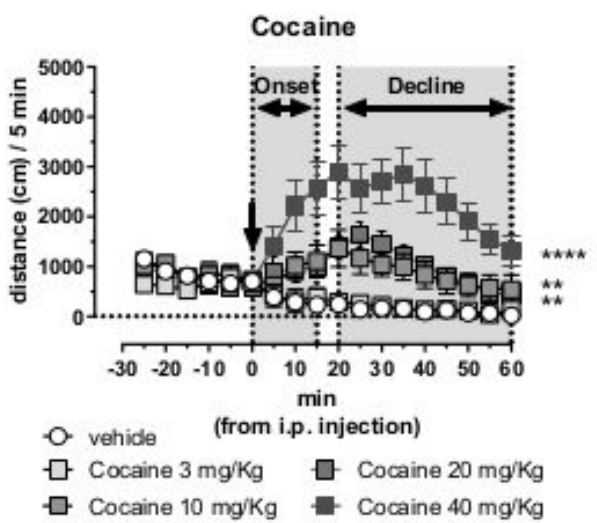

d

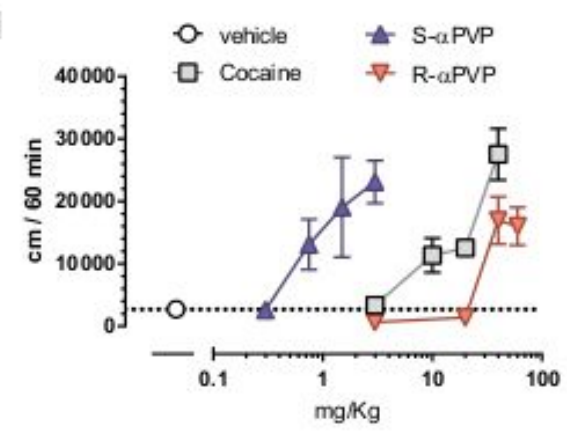

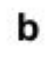

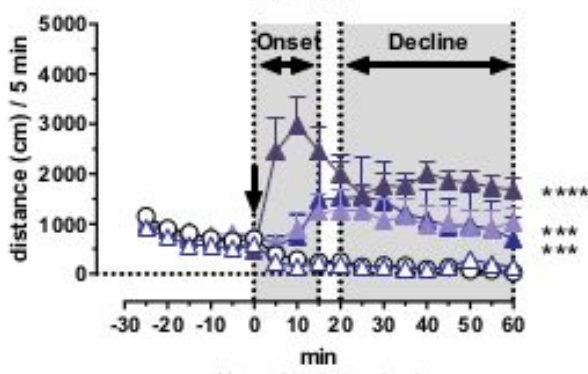

-o vehicle (from i.p. injection)

$\triangle$ SaPVP $0.3 \mathrm{mg} / \mathrm{Kg}$ - SaPVP $1.5 \mathrm{mg} / \mathrm{Kg}$

+ SaPVP $0.75 \mathrm{mg} / \mathrm{Kg}$ \& SaPVP $3 \mathrm{mg} / \mathrm{Kg}$

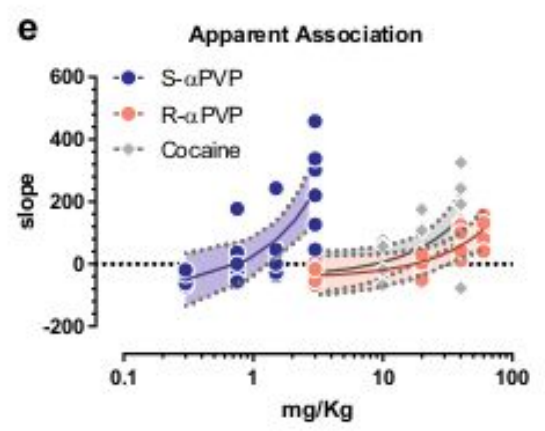

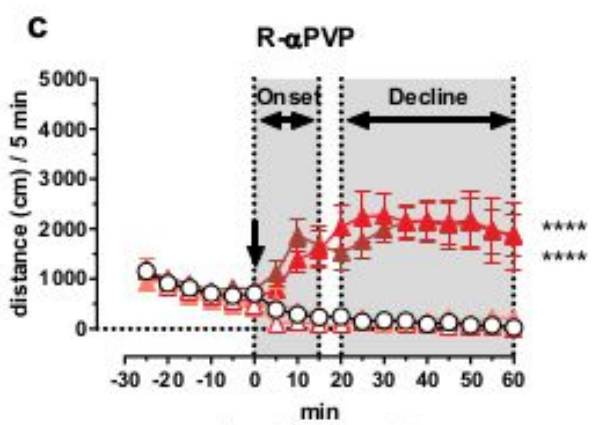

- 0 vehicle (from i.p. injection)

$\triangle$ RaPVP $3 \mathrm{mg} / \mathrm{Kg} \quad$ RaPVP $60 \mathrm{mg} / \mathrm{Kg}$

- RaPVP $20 \mathrm{mg} / \mathrm{Kg}$ - RaPVP $40 \mathrm{mg} / \mathrm{Kg}$

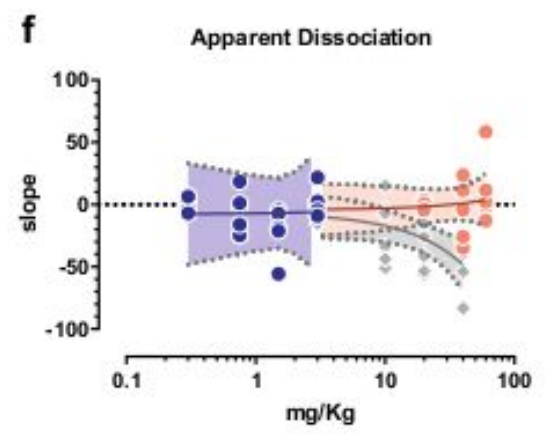

\section{Figure 5}

Time-course of the psychomotor effects elicited by Cocaine and aPVP enantiomers. a-c) Distance travelled in $\mathrm{cm} / 5 \mathrm{~min}$ for Cocaine, S-aPVP and R-aPVP, respectively. A different dose for each group of mice was injected at $\mathrm{t}=0$ (back arrow). the different doses are indicated at the bottom of the graphs. Data are mean $\pm S E M, n \geq 5$ mice/group. Statistics is conducted with One-way ANOVA followed by Dunnet's posthoc multiple comparison vs control (vehicle). ${ }^{\star} p<0.05,{ }^{* *}=p<0.01,{ }^{* \star *} p<0.001,{ }^{* \star \star *} p<0.0001$. d) the travelled distance from $0-60 \mathrm{~min}$ is summed to obtain the overall effect of the drugs and plotted against the doses injected. e) slope of the psychomotor kinetics between 0-15min from i.p injection, indicated in panels a-c as 'onset', is plotted against the effective doses for cocaine, S-aPVP and R-aPVP, respectively f) the slope of the psychomotor kinetics between 20-60min from i.p injection, indicated in panels a-c as 'decline', is plotted against the effective doses for cocaine, S-aPVP and R-aPVP, respectively.

\section{Supplementary Files}

This is a list of supplementary files associated with this preprint. Click to download.

- SuppFig1inhibitioncurrents.png

- NielloSupplementaryInfofinal.docx

- SuppFigure2ModelKapp.png 
- NielloSupplementarylnfofinal.docx

- SuppFig1inhibitioncurrents.png

- SuppFigure2ModelKapp.png 